ISSN 00156043

\title{
EDITORIAL
}

\section{Sentido de la formación ética en la universidad}

\section{Consejo de Redacción}

Resumen: $\dot{\partial}$ Pueden los actuales estudiantes universitarios, futuros profesionales cualificados, prescindir de la ética en su formación? En el mundo complejo y cambiante en que ejercerán su profesión no bastarán las intuiciones éticas comunes para responder a la segunda pregunta kantiana: ¿̇qué debemos hacer?, ¿qué valor tiene esta formación?, ¿qué valor hay que tener para afrontarla universitariamente?

Los profesionales han de tomar decisiones que tengan en cuenta el servicio a la sociedad en el ejercicio de su profesión. También los profesores, los investigadores, las personas al servicio de la universidad, incluidas las autoridades académicas, deben tener siempre presente este componente ético de sus decisiones. Es necesario que los estudiantes desarrollen, como parte de su formación, competencias éticas - reflexivas y prácticas- para el ejercicio de su profesión, lo que creemos que ha de realizarse en la universidad. En la actual crisis la sociedad espera esto de la enseñanza universitaria.

En este editorial pretendemos aportar una reflexión sobre la enseñanza y el aprendizaje de la ética en la universidad, pues, aunque conscientes de las dificultades inherentes a esta dimensión, sabemos también que esta formación es urgente y necesaria. Comenzamos preguntándonos sobre la posibilidad de esta formación, así como sobre su pertinencia universitaria. A continuación tratamos de esbozar sus contenidos y sus opciones metodológicas.

Palabras clave: enseñanza universitaria, ética cívica, ética reflexiva y práctica, función social de la profesión.

Fecha de aprobación definitiva: 18 de junio de 2012.

La versión del editorial en inglés está disponible en www.revistadefomentosocial.es desde la aparición en papel de este número. Asimismo es libre el acceso a la versión en castellano en la misma dirección. 


\section{The meaning of ethical formation in the university}

Abstract: Can today's university students, qualified future professionals, dispense with ethics in their formation? In the complex and ever-changing world where they will exercise their professions, common ethical intuitions are no longer enough, if they ever were, to answer the second Kantian question:"What should we do?", "How valuable is this formation?", "How can one go about dealing with this in the university?"

Professionals have to make decisions that take into account serving society while exercising a profession. Professors, researchers, people working in the university including academic authorities, all must always bear in mind this ethical component in their decisions. As part of their formation, it is necessary for students to develop ethical skills -reflexive and practical- for exercising their professions, and we believe that this has to be done in the university. In the current crisis, society as well expects this of university education.

The intent of this editorial is to reflect upon the teaching and learning of ethics in the university because, although conscious of the difficulties inherent in this task, we also realise that this formation is urgent and therefore more necessary than ever before. The editorial begins by contemplating the possibility of this formation, as well as its relevance in the university. We go on to outline the contents and methodological options of teaching ethics in the university.

Key Words: University education, Civic ethics, Reflexive and Practical Ethics, Social Function of the Profession.

\section{Le sens de la formation éthique à I'université}

Résumé: Les étudiants actuels, qui sont les futurs professionnels qualifiés, peuvent-ils se passer de l'éthique dans leur formation? Dans le monde complexe et changeant qui sera celui où ils exerceront leurs métiers, les institutions éthiques communes ne suffiront pas ( $n^{\prime} y$ a-t-il jamais été ainsi?) pour répondre à la deuxième question kantienne: que devons-nous faire?, quelle est la valeur de cette formation?, quelle valeur faut-il avoir pour l'affronter d'une façon universitaire?

Les professionnels doivent prendre des décisions en tenant compte du service à la société dans l'exercice de leur métier. Également les professeurs, les chercheurs, les personnes au service de l'université, ainsi que les autorités académiques, doivent toujours avoir présent à l'esprit cette composante éthique dans leurs décisions. Il est nécessaire que les étudiants développent, comme partie de leur formation, des compétences éthiques -réflexives et pratiques-pour l'exercice de leur métier, et nous pensons que cette formation doit se faire à I'université. Dans la crise actuelle, la société attend également cela de l'enseignement universitaire.

Dans cet éditorial nous voulons apporter une réflexion sur l'enseignement et l'apprentissage de l'éthique à l'université, puisque, même conscients des difficultés inhérentes à cette dimension, nous savons que cette formation est urgente, et, pour cela, plus nécessaire qu'auparavant. Ensuite nous essayons d'esquisser les contenus et les options méthodologiques de l'enseignement universitaire de l'éthique.

Mots clé: Enseignement universitaire, éthique civique, éthique réflexive et pratique, fonction sociale des métiers. 
El hombre necesita «hacerse cargo» de la situación, habérselas con las cosas -y consigo mismo-como "realidad» y no meramente como estímulos. El hombre tiene que considerar la realidad antes de ejecutar un acto; pero esto significa moverse en la «irrealidad». En el animal el ajustamiento se produce de realidad a realidad directamente. En el hombre indirectamente, a través de la posibilidad y de la libertad, que no reposa sobre sí misma, sino sobre la estructura inconclusa de las tendencias o "referencias» que abren así exigitivamente el ámbito de las "preferencias». El hombre tiene que hacer ese ajustamiento, tiene que "iustum facere", es decir, tiene que justificar sus actos. La justificación es, pues, la estructura interna del acto humano. (J. L. ARANGUREN (51972) Ética, Madrid, Revista de Occidente, 71-72; texto, adaptado, del capítulo "La realidad constitutivamente moral del hombre: moral como estructura").

\section{Introducción}

Vivimos en un mundo complejo y cambiante. La velocidad de los cambios históricos, la interdependencia global, el cuestionamiento de nuestras certezas, los retos científicos o tecnológicos, los cambios en las condiciones de vida, las profundas desigualdades sociales, el deterioro medioambiental, el poder institucional y empresarial y sus consecuencias sociales, entre otros, hacen indispensable repensar y cuestionar la ética. Ya no bastan -si es que alguna vez lo han sido- las intuiciones éticas comunes como garantía para contestar adecuadamente a la pregunta: ¿qué debemos hacer?

La sociedad reconoce cada vez más abiertamente que la vida humana, en todos sus ámbitos, debe estar regida por principios éticos, pero el mundo encara cada vez más casos de violencia ética en todos los campos del actuar humano. En este

\footnotetext{
' Como en otras ocasiones, este editorial ha contado con las aportaciones sobre el tema en un Seminario de la Revista de Fomento Social, abierto a profesores e investigadores de ETEA-LOYOLA que se celebró el 17 de mayo de 2012 en Córdoba. Fue ponente en éste el profesor de la Universidad Pontificia Comillas de Madrid, Raúl González Fabre S.I., quien asimismo es coordinador del grupo de Ética de las profesiones, constituido en UNIJES (Federación de universidades y centros universitarios de los jesuitas españoles). El editorial toma como punto de partida la síntesis, elaborada a partir de ese seminario, de un miembro del consejo de redacción de RFS, profesor Rafael Araque Padilla. Como contexto y antecedente que ha ido consolidando la reflexión sobre el tema de las universidades y centros universitarios de la Compañía de Jesús en España no queremos dejar de referirnos a la publicación de la colección "Ética de las profesiones", iniciativa en su día de la Comisión de Centros Universitarios de la Compañía de Jesús (COCESU), antecesora de la actual UNIJES, que se inició en 2002. Hasta la fecha han aparecido trece volúmenes, entre 2002 y 2011 , publicados en coedición de UNIJES con Desclée de Brouwer de Bilbao. El primero fue el texto de Xabier ETXEBERRIA, Temas básicos de ética, y el último hasta hoy es el libro colectivo del que han sido editores Augusto HorTAL y Xabier ETXEBERRIA, Profesionales y vida pública, Bilbao 2011.
} 
entorno, los profesionales tienen que asumir continuos retos y tomar decisiones con una orientación de servicio a la sociedad, tal y como se entiende la propia idea de "profesión".

Es imprescindible pues que nuestros profesionales desarrollen, como parte de su formación, competencias reflexivas y prácticas con respecto a la ética. Y podría decirse que el lugar donde esto se puede hacer es la universidad, por tratarse de la principal institución que se ocupa de la formación profesional, ciudadana y científica en las sociedades modernas.

La sociedad está demandando profesionales éticos. Sin embargo, no parece que la universidad esté respondiendo a esa demanda en los términos en que cabría esperar. Baste un ejemplo: entre las causas clave de la crisis actual que padecemos se ha señalado la codicia de muchos directivos, bastantes de los cuales se formaron en las mejores universidades y escuelas de negocio del mundo. La universidad debe asumir su parte de responsabilidad en la tarea de la formación ética de los profesionales que pone en el mercado.

Dentro de la comunidad universitaria, muchos profesores -aun estando de acuerdo con que ésta debe enseñar y formar en la condición ética de los futuros profesionales- dedican poco tiempo o esfuerzo a desarrollar metodologías que, desde sus materias específicas, permitan contribuir a la formación ética del alumno. Por otro lado, muchos estudiantes asocian las asignaturas de ética con "asignaturas relleno", que quitan tiempo para preparar otras materias, a todas luces más interesantes para su carrera profesional y sus posibilidades de empleo, o con una especie de "asignatura sermón" donde van a decirles que tienen que ser buenos, pero sin ver en qué medida esto aporta sustancia a su formación académica.

En este editorial pretendemos aportar una reflexión sobre la enseñanza y el aprendizaje de la ética en la universidad, con el convencimiento de su relevancia y pertinencia, aunque seamos conscientes de las dificultades que entraña su docencia y su implantación en la comunidad universitaria. ${ }^{2}$ La enseñanza de la ética en la universidad no es un asunto simple. Al menos cuatro cuestiones de fondo están implicadas: primero, cabe cuestionarse si puede enseñarse y aprenderse la ética; segundo, si realmente la docencia de la ética debe ser competencia de la universidad; tercero, de serlo, ¿ qué ética debe enseñarse?; y cuarto: ¿ cómo debería enseñarse? Estas serán las sucesivas partes de nuestro editorial.

${ }^{2}$ Para nuestra reflexión nos hemos servido, entre otros textos, de I. CAMACHO (1999) "Ética empresarial: reflexiones desde y para la docencia": Papeles de Ética, Economía y Dirección, 4, 33-47. 


\section{2. ¿Se puede enseñar la ética?, ¿se puede aprender?}

Algunos consideran que la educación ética es una actitud que se adquiere por medio de la educación en los primeros años de vida de la persona; otros piensan que es algo tan personal que se resiste a ser enseñado $y$, por ello, aunque la enseñanza ética puede darse en las primeras etapas de la vida, cabe dudar de la eficacia de ese empeño en los años universitarios. Sin embargo, es difícil admitir que los estudiantes sean ya adultos moralmente formados, que no precisen de ninguna educación moral. Así como es un error suponer "a priori" que las personas no tengan juicio ético, también lo es pensar que tienen un juicio ético completamente elaborado.

Es cierto que el universo ético de cada persona, su opción ética fundamental, está dotado de cierta estabilidad, pero no es algo completamente estático: el diálogo directo con otros sujetos y la apertura a la realidad misma a través de su estudio ofrecen oportunidades para reforzar, matizar o modificar las convicciones éticas de cada sujeto. No dejamos de evolucionar toda la vida en nuestra personalidad moral, y la adquisición de nuevos conocimientos puede generar cambios clave en nuestra actitud vital y en nuestras valoraciones.

La formación ética es un proceso, nunca un producto. Y, como proceso, es posible reflexionar sobre sus fundamentos y potenciar su desarrollo. Como rama del saber práctico, la ética aporta al sujeto unos contenidos y un método. Aunque ambos no lleguen a modificar las convicciones de quien estudia ética, sí le ayudarán a la reflexión ética sobre su propia realidad y la externa. Y si la ética puede aprenderse, también puede enseñarse. Es legítimo pensar que la docencia -también la universitaria- puede influir en el juicio ético de sus estudiantes.

Sin embargo, si bien pueden aprenderse modos de razonar, enfoques, teorías, etc., la práctica de la ética se adquiere con el hábito, mediante la repetición de actos, la experiencia vivida, y esto segundo ya es más difícil de fomentar. Como veremos más adelante, el binomio conocimiento-actitudes, necesario para una completa formación moral, no siempre es fácil de compaginar en la enseñanza de la ética, pues para lograrlo es preciso esperar a que comience la vida laboral.

En todo caso, el buen juicio ético requiere del desarrollo de una serie de capacidades que no se forman espontáneamente en el sujeto, aunque tampoco a través de la mera adquisición de informaciones y conocimientos. 


\section{Obstáculos a la enseñanza de la ética en la universidad}

La enseñanza de la ética en la universidad nos conduce a cuestionarnos el qué y el cómo. Es difícil dar una respuesta a ambas cuestiones sin tener presente una serie de obstáculos o dificultades que envuelven y condicionan la tarea docente. A continuación se exponen algunos de esos obstáculos que nos parecen más relevantes.

\section{I. Universidad y contexto: mercado y sociedad civil}

Nos encontramos ante dos cambios. Por un lado, el llamado marco o espacio europeo de educación superior (EEES), al que de forma simplificada nos referimos como "Bolonia", nos sitúa ante algunas dificultades que, a su vez, son oportunidades.

Como sabemos, los contenidos conceptuales no son los únicos componentes importantes de la formación universitaria, sino que el conjunto de la actividad formativa de los estudiantes también debe serlo; por otra parte, la flexibilidad es una característica relevante del EEES. La apertura de los contenidos a aspectos prácticos, axiológicos y de inteligencia emocional, combinada con la flexibilidad metodológica, se pueden considerar como factores de novedad que, ofreciendo inicialmente dificultades, abren vías aprovechables como posibilidades.

Por otro, las universidades -no sólo las privadas o las de iniciativa social, también las públicas- están hoy obligadas a competir entre sí para captar el mayor número de estudiantes que les asegure no solo su supervivencia, sino también los recursos pretendidos para desarrollar sus proyectos educativos. Esto les induce a ofrecer un producto atractivo para los alumnos potenciales. En gran medida ese atractivo reside en garantizar un empleo. Actualmente, buena parte de los alumnos, al elegir una determinada universidad, se mueven por el miedo a quedarse fuera del sistema: no encontrar trabajo o fracasar profesionalmente. Las universidades cuyas respectivas titulaciones "garantizarían" más posibilidades de empleo son las elegidas. Vivimos en la era de los "rankings" y, por ello, es complicado que la universidad permanezca al margen de ellos, pues esa ausencia mermaría sus posibilidades de captación de alumnos y de recursos.

Estas circunstancias fuerzan a la universidad a un mayor acercamiento a las necesidades y demandas empresariales, desviándolas en parte del ensimismamiento que a veces se les supone, en una competencia por ganar notoriedad entre empleadores y futuros alumnos, a quienes tratan de garantizar el empleo y el éxito en el mercado. Aun cuando esto tiene aspectos indudablemente positivos, también encierra algunos riesgos: 
- El objetivo de formación humana puede verse reemplazado por el de preparar para conseguir el éxito, un éxito entendido como dinero, buen empleo, reconocimiento social, prestigio, "status"... Parece que se prioriza el éxito individual, dejando en segundo término el servicio a toda la sociedad.

- La universidad está obsesionada en adaptarse por encima de todo a las exigencias del entorno, potenciando una enseñanza que reproduce las estructuras existentes, a costa de perder en parte su carácter de instancia crítica de la sociedad.

- A los alumnos se les transmite una imagen de una sociedad fuertemente competitiva, donde los comportamientos cooperativos (ganar-ganar) quedan relegados frente al individualismo maximizador de la simple ganancia. A fin de cuentas, se está instrumentalizando a la universidad, percibida y reducida a ser un medio para alcanzar el éxito individual.

- Existe además un riesgo de hiper-especialización, con un sesgo eminentemente técnico frente a la formación integral de la persona.

- Los saberes se tecnifican, potenciando su carácter pragmático y la capacidad simplificadora y reductora de cuantificarlo todo (sólo existe aquello que es medible), mientras se ignoran las consecuencias humanas y sociales de estos saberes.

En el mundo de la empresa hoy se están reclamando universitarios con formación ética. Pero, a menudo, tras esta demanda subyace una idea cuestionable de la ética: una ética en sentido conductista, donde es posible programar profesionales para que sean buenos de acuerdo con un estándar preestablecido de comportamientos. Pero ¿̇no debería la ética aportar un elemento de reflexión y de cuestionamiento continuos ante la realidad social?

\subsection{Resistencias de los docentes}

La docencia de la ética encuentra resistencias en la propia comunidad universitaria, tanto por parte de profesores como de alumnos ${ }^{3}$. En gran medida, estas resistencias tienen que ver con una cierta falta de claridad sobre el concepto de ética que se maneja.

${ }^{3}$ Cfr. F. Vallaeys, El desafío de enseñar ética en la universidad, en http://www.redivu.org/docs/ publicaciones/Vallaeys_Francois_ensenar_etica.pdf 
A continuación vamos a enumerar algunas resistencias que pueden darse en los propios profesores universitarios:

- La pretensión de que la enseñanza debe ser neutral, porque la ciencia también lo es.

- En consonancia con este rigorismo cientificista, encontramos a quienes cuestionan el "status" de racionalidad científica de la ética, relegándola al ámbito de la opinión o de las convicciones personales, en un mundo en el que impera el pluralismo: ¿por qué unos valores sí y otros no? Así, si se quisiera enseñar ética en la universidad, sería imposible ponerse de acuerdo sobre el qué. Este pluralismo axiológico llegaría a provocar que la ética quedase relegada a un relativismo incompatible con el quehacer científico universitario.

- Otros docentes rechazan la integración de la ética en la enseñanza por asociarla con la moral religiosa. Se genera así un pretendido distanciamiento como si la religión no pudiera aportar nada al debate moral y, por otro, se la quisiera reducir y hacer depender a la moral únicamente de la religión. Sin negar que las religiones tienen una dimensión ética que les es inherente, es inadmisible que sólo se pueda hablar de ética desde una determinada religión. En la docencia universitaria de la ética esta relación debe quedar clara, tan clara como la autonomía de la ética como saber científico con su racionalidad propia.

- Por otro lado, no es raro que exista un cierto temor a que la inclusión de la ética en el currículo universitario pueda poner en tela de juicio muchos de los contenidos enseñados en otras disciplinas.

- La falta de conocimientos suficientes sobre ética suficientes entre el profesorado es otra dificultad con que, en un nivel más práctico, nos encontramos. Aunque no todo docente universitario puede ser profesor de ética, sería deseable en todos una cierta inquietud por la dimensión ética de lo que enseñan. Pero este equilibrio entre conocimiento de la propia disciplina y conocimiento ético no es fácil de conseguir, a no ser que exista una reflexión y apoyo real por parte de la institución universitaria.

- Otras veces, se invoca la dificultad de evaluar objetivamente una asignatura como la ética, sus contenidos y sus resultados, dada la componente personal de las propias convicciones. ¿̇Cómo es posible determinar si se está aplicando bien o mal la formación ética?, ¿̇cómo se puede evaluar el conocimiento adquirido por los alumnos y su puesta en práctica? En último término hay que 
aclarar qué es lo que se evalúa: evidentemente no se evalúan las convicciones personales, pero sí es posible evaluar los conocimientos y las habilidades a la hora de aplicarlos a la resolución de problemas prácticos.

- Algunas veces, incluso, se rechaza el planteamiento de las cuestiones éticas durante la docencia de una disciplina científica, por el temor a que de este modo lleguemos a explicitar los valores que personalmente nos mueven, lo que para muchas personas resultaría incómodo e inaceptable, especialmente en un contexto de supuesta asepsia científica.

\subsection{Resistencias de los alumnos}

Por parte de los alumnos puede haber resistencias: percepciones como "pérdida de tiempo", "cursos relleno" o "inutilidad" obstaculizan cualquier intento de enseñar ética en la universidad. A ello pueden sumarse una serie de consideraciones:

- La mera existencia de un curso de ética puede percibirse como un reproche sobre la ética personal de los individuos, lo que puede suscitar rechazo o simplemente indiferencia.

- Muchos alumnos se aproximan a la ética con gran escepticismo: consideran que la ética nos traslada a un terreno ideal, con pocas implicaciones prácticas, y que resulta por tanto poco útil para su formación. El mundo profesional se mueve en otras coordenadas; todo lo que salga de esa expectativa no pasa de buenas intenciones, carentes de interés para el mercado profesional.

- El escepticismo de muchos alumnos se une a una colección de certezas que obtienen mayoritariamente del universo mediático, aunque también de partidos políticos, ONG... Están convencidos de que hay un territorio de lo "políticamente correcto" y de lo socialmente aceptable, y de que tienen que atenerse a ese espacio.

- No es raro de que los alumnos se aferren a algunas certezas que les instalan en un mundo de confort en el que no se dejan cuestionar fácilmente. Las dificultades para razonar no son ajenas a esta postura "confortable" o cómoda, algo que ciertamente se arrastra desde etapas formativas anteriores.

- Los alumnos adolecen de cierta falta de prudencia. Pueden sostener conclusiones que son absurdas sin darse cuenta de su incoherencia. Por otra parte, puede 
faltarles contacto con la realidad o estar instalados en cierto relativismo defensivo: "mis convicciones son tan buenas o tan malas como cualesquiera otras".

- Muchos estudiantes tienen una visión instrumental de la educación universitaria: "sólo sirve lo que es útil para mejorar mis posibilidades de empleo". Ése es incluso el mensaje que reciben del ambiente en que viven. Pero para esta finalidad se puede dudar de la "utilidad" de la ética; incluso se puede sospechar que, más que ayudar, en ocasiones puede ser un obstáculo.

- Los alumnos, en cuanto hijos de su tiempo, son sujetos bastante pragmáticos: les interesa la relación entre coste (esfuerzo) y beneficios (calificaciones). Si algo no se califica está fuera de su interés. El sistema de incentivos (calificaciones) no contribuye a la formación ética, pues hay muchos aspectos intangibles que no se pueden valorar y quedan fuera de la educación formal y de los intereses reales de los alumnos. ${ }^{4}$ La motivación interna está inhibida, no se favorece la virtud, esto es: el deseo de aprender.

\section{Enseñar ética, pero... ¿qué ética?}

De la enumeración anterior aparece claro un problema para la formación ética: ¿cómo se puede animar, fomentar y motivar?

\section{I. La tensión entre conocimientos y actitudes}

La cuestión sobre qué debe enseñarse encuentra una tensión permanente entre un enfoque que pone más acento en lo cognoscitivo y otro que lo pone en el cambio de comportamientos o actitudes. El primero insiste en el conocimiento de aquellas estructuras que generan injusticias o minan la cohesión social y, a partir de aquél, educar en valores y actitudes; el segundo busca el cambio de los comportamientos o actitudes. No es fácil llegar a equilibrar ambos planteamientos.

Para algunos el conocimiento racional es el camino más eficaz para un comportamiento ético; piensan que el mismo conocimiento científico produce espontánea-

\footnotetext{
${ }^{4}$ Podemos subrayar, sin embargo, que aquellos alumnos que hacen actividades de voluntariado, que suelen ser en su mayoría procedentes de colegios religiosos, se mantienen más interesados por la formación ética, aunque de hecho estas actividades no sean generadas en la universidad
} 
mente la reflexión y la disposición ética. Esta posición subordina la formación en valores a un conocimiento crítico de la realidad y de la práctica profesional que en ella se desarrolla.

Sin duda, es de gran importancia promover el desarrollo y la densidad cultural de nuestros estudiantes; algo cada vez más difícil a causa de la "hiperespecialización" técnica que domina en la universidad. Ese desarrollo es el mejor camino para la integración de conocimientos que tengan carácter ético o que planteen cuestiones social y moralmente controvertidas. El saber y el estar bien informado son cualidades no sólo intelectuales, sino que poseen también una clara dimensión ética, al tratarse de valores que permiten tomar decisiones con mayor criterio en sociedades complejas como la nuestra y que tienen repercusiones y generan responsabilidades con impacto evidente en la calidad y dignidad de nuestras vidas y de las ajenas.

Sin embargo, hay razones para dudar de que la toma de conciencia y la comprensión racional de la práctica profesional basten para realizar en la universidad la tarea de educar en lo moral. ¿Es la simple comprensión racional suficientemente motivadora para generar el hábito del cuestionamiento ético? Un enfoque meramente cognitivo hace que la traducción de la posición intelectual de cada sujeto dependa de su coraje moral para la acción ética, incluso en un medio que invite a lo contrario. Por eso nos preguntamos: $\dot{\imath}^{\text {no }}$ puede hacerse más? $\dot{i}^{\text {No estamos }}$ renunciando a los beneficios de un aprendizaje basado en la participación en acciones concretas? Los valores, más que analizándolos, se aprenden viviéndolos y experimentándolos.

En el medio universitario hoy se va imponiendo un amplio consenso en cuanto a la necesidad de desarrollar la argumentación y el debate moral. No menos importantes -forzoso es reconocerlo- son las estrategias para abordar la dimensión más afectiva (sentirse motivado y comprometido) y más práctica (capacidad de hacer algo juntos).

Si enfocamos la enseñanza y aprendizaje de la ética como educación en valores nos encontramos ante el espinoso problema de qué valores enseñar, más allá de unos mínimos globales generalmente asumidos. La educación en valores también nos sitúa en una zona peligrosa entre el adoctrinamiento o moralización y un cierto relativismo o subjetivismo radical. A nuestro modo de ver, la enseñanza de la ética debe partir de una ética cívica de mínimos, siempre con una apertura al diálogo entre las distintas éticas de la felicidad o de la vida buena. La ética cívica ha de partir de la transmisión de unos valores y de la denuncia de unos contravalores, ambos -trasmisión y denuncia- socialmente aceptados y defendidos como tales 
por la mayoría de sociedades democráticas plurales, como la Declaración de Derechos Humanos o el Pacto Global de Naciones Unidas, entre otros convenios reconocidos.

La ética personal es esencial para la formación moral, pero no puede olvidarse la dimensión social y compartida que nos une con el resto de personas de una comunidad, tanto en éticas de máximos morales, que tienen una vocación de publicidad y la paralela resistencia a privatizarse, como en la ética cívica que fundamente una ética social compartida que oriente el comportamiento colectivo de las instituciones, los agentes y otros actores de la sociedad civil, incluidos los poderes públicos, las empresas o el conjunto del cuerpo políitico.

Un horizonte flexible y dialógico que sirva para una interpretación coherente del consenso normativo de la sociedad permitirá la existencia de un ética cívica sustantiva. La mayoría de las constituciones democráticas expresan ese núcleo "duro" de valores objeto de la hermenéutica ética, de lo que ha venido a llamarse "ética de mínimos morales" compartidos. Ciertamente ese núcleo duro está bien definido, aunque de forma porosa, entre la rigidez de éticas de máximos omnicomprensivas y la vacuidad de éticas puramente procedimentales que sólo regularían los métodos para llegar a acuerdos, es decir la pura "nada" moral.

Entendemos esta exigente ética cívica de mínimos como la que puede fundamentar y sustentar el cuestionamiento crítico, epistemológico, creador y argumentativo ante lo realmente existente: lo real es algo más que lo que fácticamente se nos presenta como conjunto fenoménico de las cosas.

\section{2. Ética general y Ética profesional}

Normalmente cuando se habla de enseñanza ética en la universidad se piensa en la ética aplicada a una determinada área de actividad: la empresa, la medicina, la educación, el derecho, la ingeniería... La experiencia muestra, sin embargo, que es conveniente tomar las aguas desde más arriba y comenzar presentando algunos conceptos generales de ética.

Esta opción permite precisar conceptos, ampliar el ámbito de la ética, salir al paso de ciertos preconceptos éticos implícitos de forma poco crítica en una buena parte del alumnado y de nuestra sociedad. Todos los individuos emplean alguna forma de argumentación cuando se les plantea algún problema ético. Muchos estudiantes piensan que las decisiones éticas son una cuestión de aplicar únicamente el sen- 
tido común o práctico con el que habitualmente se manejan. Sin embargo, como dijimos anteriormente, ese "sentido común" está repleto de pre-conceptos, lugares comunes o certezas que han sido aprehendidas desde el exterior con escasa criba crítica. Es por ello preciso dotar a los alumnos de enfoques que amplíen y mejoren su razonamiento ético.

Porque la ética no es solo cuestión de sentido común, como a veces se quiere hacer creer: exige una cierta sensibilidad para captar los valores y para descubrir que la dimensión ética es inherente a toda actividad humana; exige también una cierta capacidad para situar las normas y los principios en el marco de unos valores de donde reciben su sentido último, superando así una ética reducida a normas; y exige por fin una cierta disciplina en el razonar que permita también distinguir entre razones fundadas y prejuicios o tópicos al uso.

Todo esto, que es necesario para adentrarse en la ética aplicada, no debe darse por supuesto, porque desgraciadamente nuestros alumnos son hijos de una época en la que no se cultiva el rigor del razonamiento ético, el cual queda muchas veces inmolado en el altar de un falso respeto a la conciencia individual.

Por consiguiente estamos ante un "instrumental" ético que nos permitirá movernos con más soltura, con un lenguaje común y unos presupuestos compartidos, en el terreno de la(s) ética(s) aplicada(s). Y, ya en este terreno es preciso ante todo establecer un diálogo abierto con las ciencias particulares para no caer en un discurso ético tan general y abstracto, reducido prácticamente a grandes principios, que sólo sirve para ocultar malamente la falta de competencia para enfrentarse con la complejidad de lo real.

El futuro profesional debe aprender tanto los principios morales o éticos como su aplicación a situaciones concretas de su profesión. Ambos enfoques se necesitan mutuamente. Un enfoque puramente aplicado corre el riesgo de convertirse en un conjunto de recetas no siempre adecuadas o útiles para ser aplicadas en toda situación. Éste es uno de los problemas de la formación ética basada exclusivamente en códigos, algo muy habitual en países anglosajones.

Hablar de ética aplicada implica también colocar en mejores coordenadas la ética profesional evitando que ésta derive en enfoques demasiado individualistas. El individualismo puede llevar al profesional a aislarse del entorno, ignorando los efectos de la misma y viéndola sólo como concreción de las "virtudes" personales. La ética profesional tiene que tomar como punto de partida, no tanto el comportamiento, virtuoso o no, de un individuo, sino la función social de la profesión, lo 
que la sociedad espera de ella y lo que le exige. Al profesional le compete velar, junto con sus colegas, para que su profesión sea vista con aprecio, respeto y confianza por parte de la sociedad. La ética profesional o aplicada en la formación del universitario es un referente fundamental. Constituye una ayuda a la reflexión sistemática sobre el servicio específico, las principales obligaciones y los posibles conflictos éticos con que va a tener que enfrentarse quien aspira a asumir responsable y lúcidamente el ejercicio de su profesión en beneficio de la sociedad.

Más aún, esta función social de una profesión desborda el ámbito mismo que le es específico y tiene una repercusión indiscutible sobre la sociedad en general, sobre las costumbres y valores que imperan en ella y sobre las instituciones que la estructuran. Con esto nos situamos de lleno en lo que hemos llamado la dimensión social de la ética, que se refiere a nuestros juicios y acción indirecta sobre las estructuras e instituciones de la sociedad. Es cierto que esas estructuras no dependen inmediatamente de la acción directa y de la responsabilidad de un profesional, pero la actividad de muchos profesionales, competentes, cada uno en un área especializada de la actividad humana, contribuirá a sostener o a cambiar la sociedad. Esta dimensión de la actividad profesional y de la ética aplicada no puede ser olvidada bajo el criterio de que solo merece la pena preocuparse de aquello que cae bajo la responsabilidad directa e inmediata del individuo que ejerce una profesión.

\section{Del “qué” al “cómo"}

\section{I. Sobre el discurso y la pedagogía}

El discurso de la ética no puede ser dogmático, ni tampoco presentarse a los estudiantes, bajo la pretensión de imparcialidad, como un discurso aséptico, tan ingenuamente tolerante que derivaría en un puro relativismo moral. No se debería limitar a una exposición fría de los diversos enfoques y autores sin priorizar ni valorar. Entre otras razones porque esa supuesta imparcialidad ya supone un posicionamiento ético. Además, se corre el riesgo de convertir un curso de ética en un curso de historia de la filosofía moral, en la cual se revisasen una serie de concepciones filosóficas, dejando al alumno abrumado por tantas posiciones y conceptos. El docente de ética no puede dejar de implicarse, argumentando convenientemente sus valoraciones y exigiendo, al mismo tiempo, buenas razones para ser refutado. Para ello hay que trabajar con los estudiantes las formas de razonar y de argumentar, considerando en cada momento a éstos como sujetos 
libres y autónomos en su juicio moral, capaces de racionalidad y responsables de sus actos. Pero este respeto no está reñido con la propuesta de unos valores por los que el docente apuesta y que pueden servir para cuestionar o enriquecer la posición de los alumnos.

Si la ética tiene una dimensión relacional o comunitaria esencial, de búsqueda compartida sobre lo que nos conviene como grupo humano, los alumnos tienen que percibir ese proceso de construcción e implicarse en él. No se trata sólo de adquirir conocimientos, sino además de aprender a razonar en un ambiente de diálogo, donde la implicación del profesor provocará una corresponsabilización enriquecedora del alumnado. Una actitud del profesor con este talante incrementa su autoridad moral ante sus alumnos y contribuye a desactivar posibles resistencias para provecho de todos. El docente tiene que guiar los razonamientos y el diálogo, implicándose -no puede limitarse sólo a esclarecer o clarificar los valores de cada estudiante- pero sin imponer sus ideas basándose sólo en la autoridad que le confiere su posición -a modo de "prédica" de buenas acciones y propósitos. La labor de los docentes de ética es impartir algún sentido de orden, algún esquema de disciplina, al sentido y conciencia que ya existe.

En muchos casos quedará patente que el punto de vista del profesor no es el único razonable y que existen otras interpretaciones y propuestas; más aún, que no carece de interés el conocerlas. Al mismo tiempo, esa preocupación por la educación en la inculcación de valores debería partir de un análisis de la realidad, de la sensibilización ante los problemas que se plantean en ella y de las posibilidades de introducir cambios, personales o sociales, mucho más que de un juicio moralizante que procediese de una referencia ética abstracta, deseable como utopía aunque lejana de las posibilidades reales que contribuye a que los estudiantes tengan una inequívoca percepción de su inutilidad.

Todo lo que estamos diciendo conduce a otra cuestión: ¿quién debe enseñar ética? ¿qué condiciones y qué preparación se debe esperar de un profesor de ética? Naturalmente, para acercarnos al análisis de la realidad necesitamos un profundo conocimiento de la profesión que se enseña y de las consecuencias de su ejercicio. En la universidad sin embargo solemos encontrar profesores con formación ética, aunque con escasos conocimientos sobre la profesión cuya ética enseñan, o bien expertos en una disciplina con escasa formación ética. Lograr que el profesor de ética adquiera un nivel aceptable en estas dos áreas no es fácil y desde luego exige estrategias que deben ser objeto de la política universitaria. Al final volveremos sobre esta cuestión. 
En resumen, la inclusión de la ética en la docencia no es sólo cuestión de modificar el plan de estudios o de incorporar una nueva materia. Es, sobre todo, un cambio de perspectiva en relación con lo que hoy representa lograr un buen nivel de formación universitaria, y con lo que debería significar el compromiso con los problemas sociales de una universidad que pretende formar buenos profesionales y buenos ciudadanos.

\subsection{Integrando la ética en el currículo universitario}

La integración de la ética en la formación universitaria puede hacerse con diversos planteamientos. Por ejemplo, la ética puede integrarse como asignatura obligatoria $u$ optativa en las diferentes titulaciones universitarias o de posgrado. Ambas alternativas tienen sus ventajas e inconvenientes. Como asignatura optativa permite que los que se matriculen en ella lo hagan porque tienen un interés positivo por abordar este tipo de reflexión, aunque pueden mezclarse otras razones más pragmáticas (facilidad para aprobarla, horario cómodo...). La motivación del alumnado que viene libremente a cursarla permite trabajar de forma más eficaz y gratificante.

En el otro caso, podemos encontrarnos no solo con la indiferencia del alumno hacia cualquier tipo de asignaturas, sino una positiva resistencia hacia lo que se considera una exigencia no justificada; pero la obligatoriedad también tiene ventajas innegables: el reconocimiento de la ética como una disciplina científica, aunque su racionalidad sea diferente de la racionalidad técnica; la apuesta por la dimensión ética de la realidad como algo que forma parte del estudio de cualquier parcela de la actividad humana. Las dificultades de esta alternativa deben ser paliadas mediante un adecuado tratamiento de los prejuicios en que se basa su rechazo.

Una tercera posibilidad -transversalidad- es la incorporación de la ética a todas las asignaturas, siendo responsabilidad de los profesores. Teóricamente, esta solución parece excelente: es la que mejor integra que lo ético forma parte de la realidad profesional. Pero tiene sus problemas: disposición y preparación de los profesores, escasa probabilidad de que los alumnos perciban la ética como un saber autónomo con su propia racionalidad y método específico; por último, esta solución corre el peligro de diluirse en algunas consideraciones de prudencia que se añaden al estudio de cada tema o problema.

La integración de la ética en los planes de estudio debería, a nuestro juicio, tener tres elementos principales: 
- Un curso de ética básica o fundamental, autónomo, situado en los primeros años de la carrera, donde se presentan el enfoque general de lo que es la ética y las grandes líneas de una ética profesional. Serviría para dotar a los alumnos de una mayor capacidad argumentativa ante los conflictos éticos.

- Un curso de ética profesional, general y aplicada, en el segundo tramo de la carrera, donde se aborden los problemas éticos específicos de la profesión que se estudia.

- Una presencia de la ética en otras materias, de forma más diluida o con expresa consideración incluso en el programa, donde se coadyuvara al reconocimiento de la dimensión ética en la materia de conocimiento de que se trate.

El planteamiento anterior tiene la ventaja de que puede dar lugar a que un grupo de profesores de asignaturas afines, o incluso muy diferentes, constituyan un equipo de reflexión ética que profundice sobre la dimensión ética de sus materias y estudie la forma de darle cabida en el desarrollo de sus programas. A medio plazo, una praxis así repercutirá sobre la cultura de todo el centro; no sólo sobre los contenidos de la docencia, sino sobre todas las relaciones profesor-alumno, sobre el comportamiento de toda la comunidad universitaria y sobre la estructura y funcionamiento del centro.

\section{La universidad como referente ético}

\section{I. Un replanteamiento de la formación}

La formación ética requiere volver al concepto clásico de formación: racionalidad, afectividad y practicidad (prudencia). Las cosas no son como las imaginábamos, pero hay que seguir con un proyecto moral en medio de la resistencia que se encuentra en la realidad. Hay un elemento de afecto en la formación del sujeto. La universidad es una institución que se siente muy neutral con relación a los afectos y los relega a los márgenes de la misma. Parece que lo único que importa es la profesionalización. Se comprimen más cosas en menos sitio y al final sólo queda lo conceptual. En los años universitarios, los alumnos no acaban de madurar afectivamente

Lo que nos encontramos generalmente es una fragmentación. La persona humana está despiezada. El elemento racional es el crucial, y es además lo que suele exi- 
girse al alumno para graduarse. Es fácil dar la clase de ética, pero es más difícil recomponer en la universidad el "puzzle" de la educación moral genuina.

La sociedad ha de exigir a la universidad un nuevo perfil de egresado, un profesional en el sentido completo del término; una persona formada técnica y humanamente, sensible a los retos que enfrenta la construcción de un mundo más justo; un estudiante informado, capaz de orientar su actividad profesional hacia el bien común, con capacidad de escucha y diálogo. Para ello es preciso integrar la cultura humanista con la cultura científica. Hay que "desfetichizar" el saber enseñando al estudiante no sólo el dato informativo, sino cómo se llegó a ese dato, es decir enseñándole a conocer el conocimiento.

La ética debería venir acompañada de experiencias de trabajo con las víctimas. El contacto directo con la pobreza, la marginación o la discriminación contribuirían a formar a gente muy distinta. Y ello tendría que venir de la mano de un reconocimiento oficial de créditos en el currículo universitario.

Una ética bien aprendida por el estudiante le permitirá acostumbrarse a respetar la ética por el mero principio de ser un valor humano importante y satisfactorio, y de allí a respetar la ley por ser también un valor social, más que por temor a ser castigado si actúa ilegítimamente. Se trata de enseñar el valor humano de la ética "per se", y no por necesidad de supervivencia o conveniencia para no ser molestado en su práctica profesional. Esto le ayudará a ser persona íntegra y comprometida con sus principios en todos los ámbitos de su vida. También aprenderá a ser sistemáticamente coherente con sus principios y a no desoír a su conciencia.

\subsection{Una universidad orientada hacia la ética}

Si hay una institución social que debería ser un referente ético en la sociedad, esa es la universidad. Pero ese activo no se le puede presuponer en los tiempos que corren. La incorporación de cuestiones éticas y la modificación o creación de condiciones que hagan posible que el escenario de aprendizaje universitario también lo sea de aprendizaje ético requerirá sin duda un esfuerzo institucional bien planificado y decidido.

En la universidad, la ética se capta mucho más de lo que se enseña. De ahí la relevancia de generar una cultura universitaria de lo ético, un nuevo clima organizativo donde más allá de la docencia de unas asignaturas de ética, la universidad busque la ejemplaridad en la práctica cotidiana, en la manera de abordar la docencia y la manera de ejercerla. Corresponde a todos los que trabajan en ella, 
encabezados por sus dirigentes, gestionar eso que en el ámbito empresarial se denominan los "momentos de la verdad": nos la jugamos en cada momento de relación con los alumnos.

Necesitamos una cultura universitaria que instituya la ética como tema transversal prioritario en todas las carreras y que provea de los medios necesarios para formar a sus profesores en el enfoque de integrar los saberes en el marco de los problemas éticos. No puede abandonarse el interés por lo ético a la motivación personal o a la buena voluntad de cada profesor. El alumno tiene que percibir que la dimensión ética es una constante en su formación universitaria que debe resonar en otras asignaturas. Hay que comenzar involucrando a los profesores de otras disciplinas: que los alumnos vean qué "problemas" existen y que perciban que lo tecnológico no es un axioma indiscutible. Los seminarios interdisiciplinares con los profesores afectados pueden ser muy útiles para esta mutua implicación. Las sinergias pueden generar un gran impacto.

La formación ética debe ser complementada con la investigación. El enriquecimiento de la ciencia social puede ayudar a construir el pensamiento desde otra antropología, también con criterios científicos. Tirar piedras sin un fin claro es tirar piedras al vacío. Se necesita una investigación en al menos dos direcciones. Por un lado, una investigación alternativa con nuevas propuestas sociales que no sólo cuestionen el "statu quo", sino que también hagan prospectivas diferentes ante los problemas reales; propuestas que puedan transferirse a la sociedad y que contribuyan a la solución de problemas. Por otro lado, una investigación sobre buenas prácticas en la enseñanza e integración de la ética en la educación superior. Seguro que muchas universidades, entre otros los centros universitarios españoles jesuitas agrupados en la Federación UNIJES, han realizado experiencias y proyectos interesantes de los que se puede aprender mucho.

Pero también parte de la cultura universitaria tiene que ser "predicar con el ejemplo". La universidad debería gestionarse del modo más democrático, transparente y participativo posible -lo que debe ser recogido en sus Estatutos y otras normas de organización y funcionamiento- para, desde el ejemplo de su vida cotidiana, infundir los buenos hábitos ciudadanos a toda la comunidad universitaria.

Igualmente, la universidad no puede inhibirse de la presencia social en el debate público, en el diálogo sobre los retos éticos, sobre los problemas que afectan a la sociedad mundial, nacional, regional o local. Es frecuente escuchar la crítica al silencio de una institución que se ha caracterizado por el debate racional, científico, pero que no siempre baja a la arena de los problemas concretos. 
La universidad debería preocuparse por el aspecto emocional. En la educación tradicional, el profesor tiene la capacidad de generar un impacto en el alumno. No se puede descuidar el tema central: la formación del sujeto. Sin valores no hay educación. Para educar hay que hacer personas buenas. El docente es algo más que un mero transmisor de conocimiento. Tiene que enseñar a aprender ciencia, a gestionar el conocimiento de una forma significativa y con sentido personal para el estudiante. El profesor es un transmisor de valores y debería ser un referente para los alumnos.

\section{El reto formativo}

Sin duda, la integración de la ética en la educación superior representa un reto difícil para la universidad. Son muchas las necesidades a que la universidad debe dar respuesta: la adaptación a la sociedad de la información y de las nuevas tecnologías, la apertura al fenómeno de la globalización y el análisis de su impacto en los diferentes ámbitos de la ciencia, la tecnología, la economía y el mundo del trabajo, la atención a la diversidad de los estudiantes y la preocupación por alcanzar la excelencia académica, la rendición de cuentas y el establecimiento de metas, prioridades e indicadores en función de cuyos logros se puedan conseguir mejores resultados.

A estas presiones hay que sumar, como se ha señalado, las resistencias internas tanto de estudiantes, como de profesores o de la propia cultura institucional. Todas estas cuestiones complican y condicionan lo que se puede hacer para mejorar la formación ética. Pero no se puede caer en un pesimismo paralizante. Hay que intentar no someterse, renunciando a llevar a cabo un proyecto formativo y educativo. Esto es quizá algo que ha caracterizado la educación superior en los centros jesuitas. Hay que navegar entre las rocas, pero navegar. 